\title{
The Annealing Twins of Fe-20Mn-4Al-0.3C Austenitic Steels during Symmetric and Asymmetric Hot Rolling
}

\author{
Changsheng $\mathrm{Li}^{1}{ }^{1} * \mathbb{C}$, Biao $\mathrm{Ma}^{2}$, Yanlei Song ${ }^{1}, \mathrm{Kun} \mathrm{Li}^{1}$ and Jingbo Dong ${ }^{1}$ \\ 1 State Key Laboratory of Rolling and Automation, Northeastern University, Shenyang 110819, China; \\ sjunying@163.com (Y.S.); likun459621709@163.com (K.L.); neudong23@163.com (J.D.) \\ 2 CRRC Tangshan Co., Ltd., Tangshan 063035, China; mab988@163.com \\ * Correspondence: lics@ral.neu.edu.cn; Tel.: +86-24-8368-7749
}

Received: 15 October 2018; Accepted: 27 October 2018; Published: 29 October 2018

check for updates

\begin{abstract}
The present work investigates the annealing twins of Fe-20Mn-4Al-0.3C austenitic steels in symmetric hot rolling (SHR) and asymmetric hot rolling (ASHR). The average grain size is $26( \pm 9.6) \mu \mathrm{m}$ and $11( \pm 7.0) \mu \mathrm{m}$ for the tested steel in SHR and ASHR processes. The density of high angle grain boundary (HAGB) and annealing twin boundary increase with the decrease of grain size. The annealing twin is obviously higher in ASHR than in SHR. The linear relation model between the logarithm of twin boundary density and the logarithm of the grain size is established. The grain boundary migration is continuously generated during recrystallization in SHR process. The coincident site lattice (CSL) boundary proportion increases with local grain boundary continuing bugling and the migration direction of bugling grain boundary constantly changes. The tensile property of the tested steel is improved due to the effective grain refinement and high density of annealing twins caused by the severe strain in the ASHR process. The purpose of high density HAGB for austenitic steels is helpful to an improvement in mechanical properties.
\end{abstract}

Keywords: rolling; annealing; twin boundary; austenitic steel; grain refinement

\section{Introduction}

As one of the most common and easily recognized features in face-centered cubic (FCC) metals and alloys, the annealing twins have been investigated for nearly 90 years since they were first observed. The early research was motivated mostly by the origin, growth and annihilation of annealing twins in austenite [1-4]. However, in the past two decades the annealing twins started to be focused on, owing to the boom in metal and alloy development, and the proposal of grain boundary engineering (GBE). The application requirement provides a clear engineering significance for the study of annealing twins.

The research methods concerning the origin and growth of the annealing twins have also developed, including direct observation [5-7] and indirect deduction [3,4,8-10]. The former is more concentrated on in-situ formation processes, whereas the latter tends to analyze the experimental results afterwards, i.e., the final quantitative statistics of annealing twin boundary $(\Sigma 3)$ and the apparent influence of processing and microstructural factors. In most cases, the indirect method is more frequently applied. Furthermore, the formation mechanism of annealing twins in FCC metals and alloys have been proposed, based mainly on four field models: (1) growth accident [1,3,9]; (2) nucleation via stacking faults or fault packets [4,8,11]; (3) immobile boundary decomposition [12]; and (4) $\Sigma 3$ interactions related to boundary migration [13]. The latter two models have recently been proposed in twinning related GBE process. None of these models can be used singly to interpret all types of the annealing twin formation.

Randle et al. $[13,14]$ proposed the $\Sigma 3$ grain boundary reaction model to explain the formation of annealing twins. Wang et al. [15] analyzed the influence of deformation storage energy on the 
formation of annealing twins during recrystallization and pointed out that the number of twins increased with the increase of storage energy.

Although the detailed mechanism with regard to their origin has not come into full agreement, there are some general conclusions that have been widely accepted by most researchers. It follows that the annealing twins form both during recrystallization and grain growth, but primarily during recrystallization. Their existence is out of the need to reduce overall interfacial energy, which may be realized by grain boundary reorientation, or by partial dislocation emission to form stacking faults, or by immobile boundary dissociation. Moreover, the occurrence probability is associated with grain boundary mobility, while higher migration velocity usually creates more twin boundaries.

The strengthening behavior of austenitic steel is closely related to the annealing twin structure, while the annealing twin density is affected by the material preparation method and processing technology. At present, the quantitative analysis of annealing twin in austenitic steel mainly concentrates on the process of cold rolling, and the influence of some annealing parameters on the annealing twin density is also obtained. However, the research on the change of the annealing twin density in symmetric hot rolling (SHR), and after the introduction of additional serve shear deformation in the asymmetric hot rolling (ASHR) process has not been reported.

In this work, the influence of hot rolling on annealing twin density and the proportion of high angle grain boundary (HAGB) is analyzed, and the formation and evolution law of annealing twins in SHR and ASHR is revealed. The aims of the research are improving the annealing twin fraction to achieve further grain refinement for austenitic steels, because twin boundary is considered as effective intragranular interfaces to block dislocation glide and enhance the strength. The results will provide reference to improve the tensile strength of austenitic steel.

\section{Materials and Methods}

\subsection{Materials and Experiments}

The measured value of the chemical composition of the experimental steel (Fe-20Mn-4Al-0.3C) is $0.298 \% \mathrm{C}, 0.45 \% \mathrm{Si}, 20.56 \% \mathrm{Mn}, 0.006 \% \mathrm{P}, 0.002 \% \mathrm{~S}, 4.11 \% \mathrm{Al}, 0.015 \% \mathrm{~N}, 0.11 \% \mathrm{~V}$, balance Fe. The tested steel is melted at $1580-1630{ }^{\circ} \mathrm{C}$ in a vacuum induction furnace ZGB150 (Jinzhou Electric Furnace, China) during steel making. The cast ingots are forged into several billets with a size of $500(L) \times 100(W) \times$ $40(\mathrm{H}) \mathrm{mm}^{3}$. Then these forged billets are subjected to heating and process of SHR and ASHR.

Before hot rolling, 40 -mm-thick hot forged billets are held at $1200{ }^{\circ} \mathrm{C}$ for $2 \mathrm{~h}$, the morphology of microstructure of the steel is shown in Figure 1, and the average grain size of the steel was 350 $( \pm 151) \mu \mathrm{m}$.

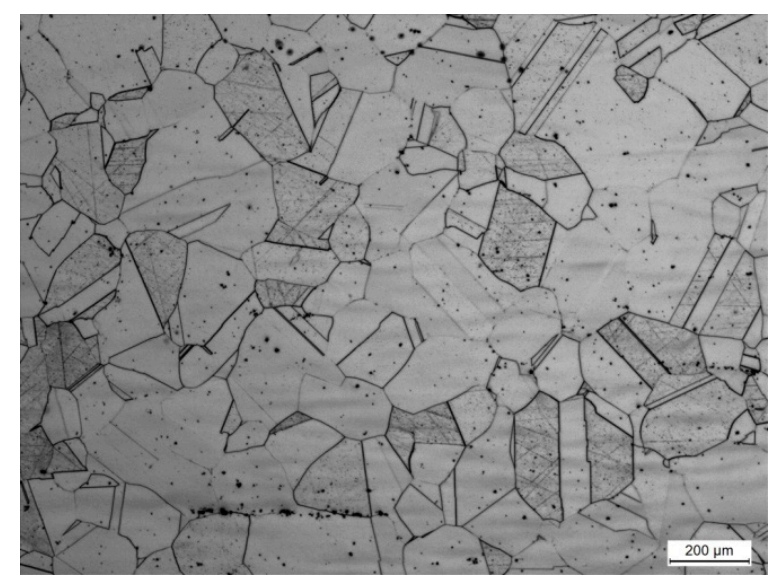

Figure 1. The microstructure of as-received Fe-20Mn-4Al-0.3C steel after soaking at $1200{ }^{\circ} \mathrm{C}$ for $2 \mathrm{~h}$. 
In SHR process, billets are hot rolled in a $\$ 450 \mathrm{~mm}$ two rolls reversible rolling mill in the laboratory. The start rolling temperature is $1100{ }^{\circ} \mathrm{C}$. Three passes samples $(40 \mathrm{~mm} \rightarrow 26 \mathrm{~mm} \rightarrow 17 \mathrm{~mm} \rightarrow 12 \mathrm{~mm}, \varepsilon=70 \%)$ are called S-p3-70\%. Five passes samples $(40 \mathrm{~mm} \rightarrow 26 \mathrm{~mm} \rightarrow 16 \mathrm{~mm} \rightarrow 10 \mathrm{~mm} \rightarrow 6 \mathrm{~mm} \rightarrow 4 \mathrm{~mm}, \varepsilon=90 \%)$ are called S-p5-90\%. Seven passes samples ( $40 \mathrm{~mm} \rightarrow 28 \mathrm{~mm} \rightarrow 24 \mathrm{~mm} \rightarrow 18 \mathrm{~mm} \rightarrow 13 \mathrm{~mm} \rightarrow 9 \mathrm{~mm} \rightarrow 6 \mathrm{~mm} \rightarrow 4 \mathrm{~mm}, \varepsilon=90 \%$ ) are called S-p7-90\%. Ten passes samples $(40 \mathrm{~mm} \rightarrow 28 \mathrm{~mm} \rightarrow 24 \mathrm{~mm} \rightarrow 18 \mathrm{~mm} \rightarrow 13 \mathrm{~mm} \rightarrow 11 \mathrm{~mm} \rightarrow 9 \mathrm{~mm} \rightarrow 7 \mathrm{~mm}$ $\rightarrow 6 \mathrm{~mm} \rightarrow 5 \mathrm{~mm} \rightarrow 4 \mathrm{~mm}, \varepsilon=90 \%$ ) are called S-p10-90\%.

The finish rolling temperature is $1020{ }^{\circ} \mathrm{C}$ for S-p3-70\% and S-p5- $90 \%$, and $920{ }^{\circ} \mathrm{C}$ for S-p7-90\% and S-p10-90\%. The hot rolled specimens are cooled by water immediately after hot rolling.

ASHR procedure is conducted on a $\phi 400$ two rolls reversible rolling mill in the laboratory. The ASHR condition is implemented via different circumferential velocities of the two working rolls with the same diameters but different rotational speeds. The velocity of lower roll remained constant and is slower than that of the upper roll. The velocity ratio (between upper roll velocity and lower roll velocity) is 1.2 in this research work. The billets before ASHR are held for $20 \mathrm{~min}$ at $1050{ }^{\circ} \mathrm{C}$. The start rolling temperature is $1020^{\circ} \mathrm{C}$, the final rolling temperature is $900^{\circ} \mathrm{C}$. Two billets are rolled at one pass ( $5.5 \mathrm{~mm} \rightarrow 2.2 \mathrm{~mm}, \varepsilon=60 \%$ ) to a thickness of $2.2 \mathrm{~mm}$ (samples are called As-p1-60\%-1, As-p1-60\%-2). Two billets are rolled at three passes $(12 \mathrm{~mm} \rightarrow 7.5 \mathrm{~mm} \rightarrow 4.5 \mathrm{~mm} \rightarrow 2.0 \mathrm{~mm}, \varepsilon=83 \%)$ to a thickness of $2.0 \mathrm{~mm}$ (samples are called As-p3-83\%-1, As-p3-83\%-2). The hot rolled plates are cooled by water immediately after ASHR process.

The specimens S-p3-70\% in SHR process and As-p3-83\%-1 in ASHR process are solid solution treated at $900{ }^{\circ} \mathrm{C}$, and the solution time is $30 \mathrm{~min}$.

\subsection{Characterisation}

The optical microscopy (LEICA DMIRM, Jena, Germany) was used to observe the microstructure of the samples. Metallographic specimens are mounted, ground and polished in a standard preparation method with 240, 400, 800, 1200 and 1500 grit emery paper, and subsequent mechanical polished with 4 and $1 \mathrm{~m}$ diamond paste. A colloidal alumina solution is utilized for final polishing. The electrolyte consists of nitric acid of $60 \%$, and the voltage, electric current and time for electro-polishing is $20 \mathrm{~V}$, $1.3 \mathrm{~A}$ and $25 \mathrm{~s}$, respectively.

Annealing twin boundary, recrystallized austenite grains and proportion of $\Sigma 3, \Sigma 9$ and $\Sigma 27$ grain boundaries are identified using electron backscattered diffraction (EBSD) (ZEISS Ultra 55, Jena, Germany) scan on a scanning electron microscope. All data are post-processed by a TSL-OIM software. The step size is selected from $0.1 \mu \mathrm{m}-1.2 \mu \mathrm{m}$, according to various grain sizes.

Vickers micro hardness distribution across the plate thickness was examined using a micro hardness tester (FUTURE-TECH FM-700, Tokyo, Japan). Tensile test at a strain rate of $1 \times 10^{-3} \mathrm{~s}^{-1}$ was performed with an Instron-type testing machine at room temperature.

\section{Experimental Results and Discussion}

\subsection{The Annealing Twins in SHR Process}

Image quality (IQ) of EBSD maps for specimen S-p3-70\%, S-p5-90\%, S-p7-90\% and S-p10-90\% in SHR process is shown in Figure 2. It can be seen that the average austentic grain size of $26( \pm 9.6) \mu \mathrm{m}$ is prepared in SHR process. The average fraction of annealing twins are $51( \pm 3) \%$ by calculation. The annealing twins in recrystallized grains reveal a higher level and a grain shape that is slightly elongated and not very equiaxed. 

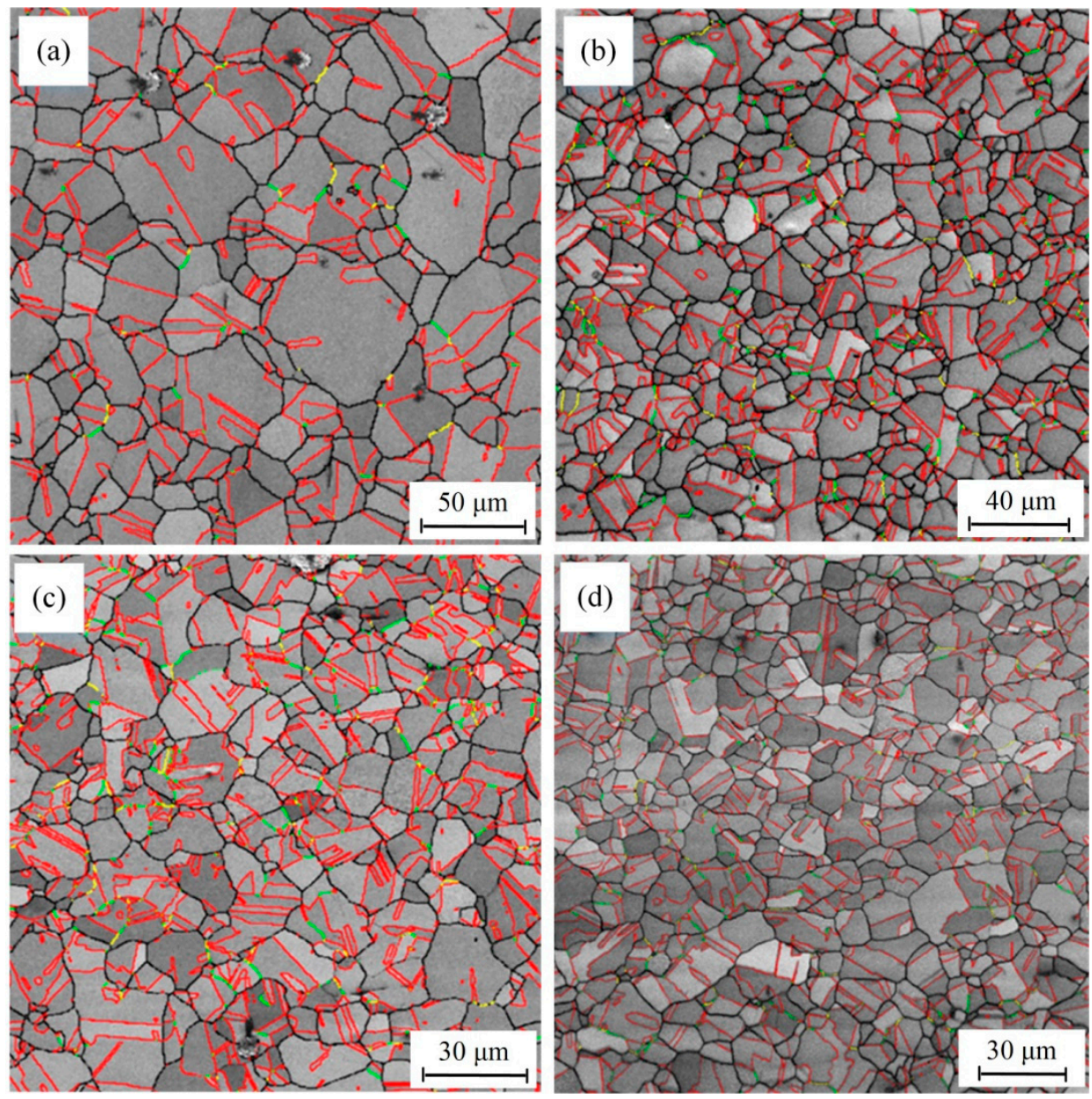

Figure 2. EBSD-Image Quality maps for the microstructure of the tested steel with different rolling schedule in SHR process.(a) S-p3-70\%, (b) S-p5-90\%, (c) S-p7-90\% and (d) S-p10-90\%. Red line indicate the anealing twin boundary, black line indicate the large angle grain boundary, green line indicate the $\Sigma 9$ grain boundary, yellow line indicate the $\Sigma 27$ grain boundary.

For the sake of analysis of the effect of manganese content and stacking fault energy on the annealing twin proportion, the effective grain size and proportion of annealing twin of hot rolled plates are followed by solution treatment at $950{ }^{\circ} \mathrm{C}$ including the self-made steel Fe-20Mn- $4 \mathrm{Al}-0.3 \mathrm{C}$ and the commercial steel Fe-27Mn-4Al-0.3C $(0.30 \% \mathrm{C}, 0.4 \% \mathrm{Si}, 26.87 \% \mathrm{Mn}, 0.005 \% \mathrm{P}, 0.003 \% \mathrm{~S}, 4.09 \% \mathrm{Al}$, balance $\mathrm{Fe}$ ). The results indicate that the effective grain size of these samples with a value of $\sim 30 \mu \mathrm{m}$ is not varied much. The annealing twins proportion of Fe-20Mn-4Al-0.3C steel (Stacking fault energy (SFE) $\left.=43 \mathrm{~mJ} / \mathrm{m}^{2}\right)$, Fe-27Mn-4Al-0.3C (SFE $\left.=52 \mathrm{~mJ} / \mathrm{m}^{2}\right)$ is $45.46 \%$ and $50.6 \%$, respectively. Compared with Fe-27Mn-4Al-0.3C steel, the decrease in manganese content of Fe-20Mn-4Al-0.3C steel results to the SFE decrease by $25 \%$, annealing twins proportion decrease by $9.8 \%$.

\subsection{The Annealing Twins in ASHR Process}

Figure 3 shows the IQ of EBSD maps of the microstructure on the surface of the tested steel in ASHR process. The microstructure of the specimen As-p1-60\%-1, As-p1-60\%-2 is shown in Figure 3a,b. The microstructure of the specimen As-p3-83\%-1, As-p3-83\%-2 is shown in Figure 3c,d. The mean grain size of the specimens is $9( \pm 2.0) \mu \mathrm{m}, 9( \pm 2.0) \mu \mathrm{m}, 6( \pm 1.6) \mu \mathrm{m}, 18( \pm 6.3) \mu \mathrm{m}$, respectively. The reason why the grain be fine during ASHR is that additional severe shear stress increases the nucleation rate of recrystallization, and reduces the grain size, compared with the SHR process. Twins morphology has two types of grain boundary cross angle (A type) and twins that are running through the grains 
(B type). Meanwhile, the annealing twins with different orientations are formed inside many of the grains. This is because there are 12 potential variants of twinning along the $\{111\}<112>$ in FCC metal. In term of single grain, only several special twinning variants can be produced during the process of the recrystallization of grain growth. Thus, it indicates that the formation of annealing twin is not in fact random and following to certain specific guide line, including reduction of total interfacial energy [16], increasing grain boundary mobility [13] or the need for rearrangement of dislocations at grain boundaries [12].
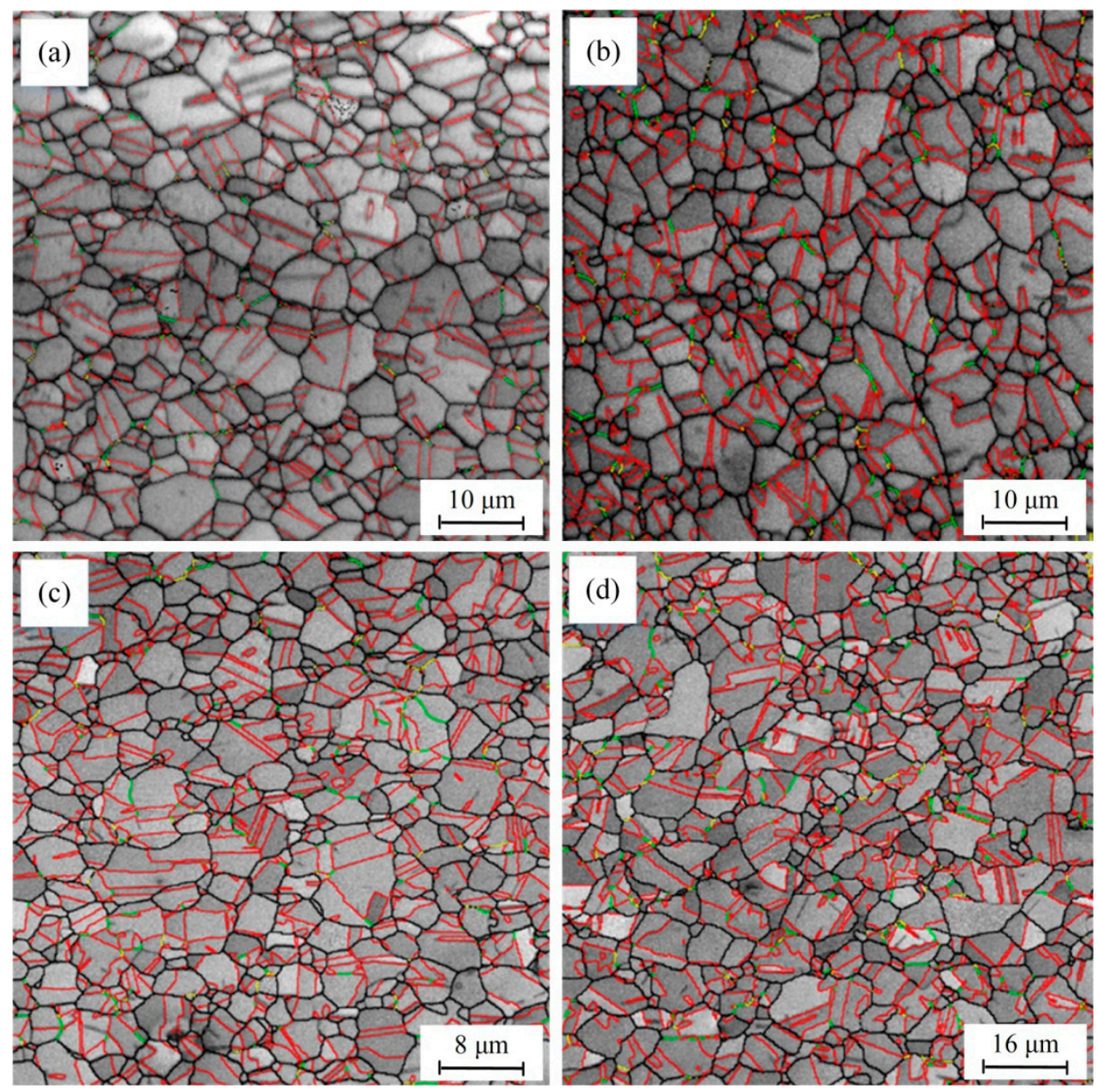

Figure 3. EBSD-IQ maps of the microstructure on the surface for the tested steel in ASHR process. (a) As-p1-60\%-1, (b) As-p1-60\%-2, (c) As-p3-83\%-1, (d) As-p3-83\%-2. Red line indicate the anealing twin boundary, black line indicate the large angle grain boundary, green line indicate the $\Sigma 9$ grain boundary, yellow line indicate the $\Sigma 27$ grain boundary.

The annealing twin nucleation always follows close behind the migrated grain boundary perpendicular to the twin boundary, which represents the migration direction of grain boundary. Because of that, it reveals that a higher quantity of twin boundary exists inside the austenitic grains, the greater degree grain boundary migrates. Meanwhile, that also indicates that during grain growth, the more the different orientation variants are obtained, the more obvious anisotropy grain boundary migrates in different directions.

\subsection{The Annealing Twins Density}

The annealing twin density refers to the surface area of the annealing twin boundary in a unit volume, which is proportional to the length of the annealing twin boundary in the unit cross-sectional 
area, and is proportional to the number of intersections between the unit length line and the annealing of the twin boundary. In this research work, the length of the annealing twin boundary in the unit cross sectional area is measured by EBSD. The annealing twin density is denoted as $N_{\mathrm{L}}$, and the unit is $1 / \mathrm{mm}$. The number of annealing twin boundary per grain is represented by $N_{\mathrm{G}}$, and the twin boundary length fraction is represented by $f_{\mathrm{TB}}$. The calculation equations of $N_{\mathrm{L}}, N_{\mathrm{G}}$ and $f_{\mathrm{TB}}$ can be seen in reference [7]. It is noted that the numbers of grain boundaries are evaluated by TSL-OIM analysis software. EBSD data are collected by a Zeiss Ultra 55 field emission SEM, and the scanning plane is a steel plate longitudinal section. According to the Brandom criterion, the allowable deviation angles of $\Sigma 3, \Sigma 9$ and $\Sigma 27$ grain boundaries are $8.66^{\circ}, 5^{\circ}$ and $2.89^{\circ}$, respectively. The step size of EBSD is determined according to the grain size and the range of step ranged from 0.1 to $5 \mu \mathrm{m}$.

Figure $4 \mathrm{a}$ shows the annealing twin density as a function of average grain size during SHR and ASHR processes. The grain size of SHR and ASHR plate is $26( \pm 9.6) \mu \mathrm{m}$ and $11( \pm 7.0) \mu \mathrm{m}$, respectively. The density of HAGB and the annealing twins decreases with the increase of grain size. It indicates that the formation of the annealing twin is obviously affected by the rolling process. The higher proportion of HAGB and annealing twin in ASHR plates has a favor to impede dislocation movement during the plastic deformation of experimental steel, playing a strengthening role in grain boundary.
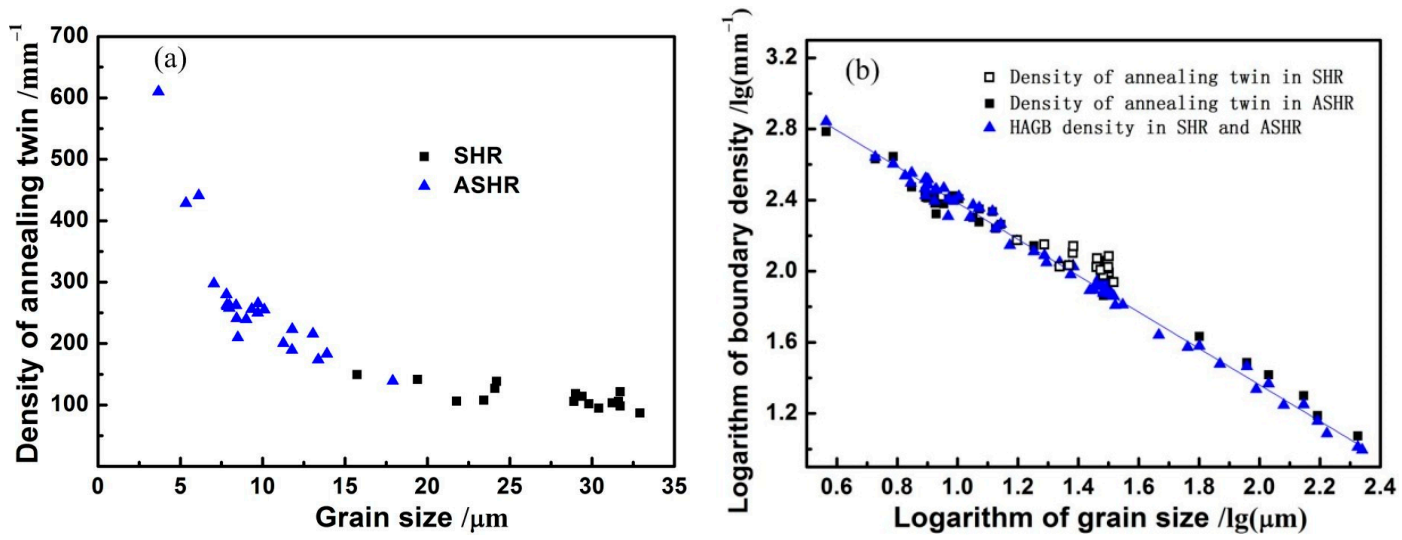

Figure 4. Variation of density of annealing twin boundaries (a) as a function of average grain size, logarithm of the boundary density as a function of logarithm of the grain size (b) in SHR and ASHR process.

Figure $4 \mathrm{~b}$ shows the logarithm of the density of HAGB and twin boundary $\left(\lg N_{\mathrm{L}}\right)$ as a function of logarithm of the grain size $(\lg D)$. The linear relation model was obtained as Equation (1).

$$
\lg N_{\mathrm{L}}=-1.02 \lg D+3.41
$$

The relation between $\lg N_{\mathrm{L}}$ and $\lg D$ is relatively discrete during SHR; in contrast, the dependence of $\lg N_{L}$ and $\lg D$ during ASHR process reveals a well-fitting linear relation. This is because the annealing twins formed on the close-packed (111) surface perpendicular to the migration direction of grain boundary has a favor to further grow along this direction, resulting in a higher proportion of the annealing twins in the ASHR process compared to that in SHR process.

\section{4. $\Sigma 3, \Sigma 9$ and $\Sigma 27$ Boundary}

The fraction of coincident site lattice (CSL) boundaries in the steel is enhanced by multiple passes hot deformation and heat treatment in GBE. During recrystallization and growth, the encounter of two coherent $\Sigma 3$ grain boundaries driven by the migrated grain boundary will create a $\Sigma 9$ grain boundary, which continues to migrating to meet other $\Sigma 3$ grain boundary, resulting to $\Sigma 3$ or $\Sigma 27$ grain boundaries. And the interactions of $\Sigma 3$ or $\Sigma 9$ grain boundaries will be more inclined to the formation of $\Sigma 3$ grain boundary with lower interfacial energy. 
Figure 5 indicates the fraction of $\Sigma 9$ (Figure 5a) and $\Sigma 27$ (Figure 5b) grain boundary in total HAGB of the tested steel in SHR and ASHR processes. As a whole, the proportion of $\Sigma 9$ and $\Sigma 27$ grain boundary in SHR is higher than that in ASHR process. The phenomenon results from the occurrence of recrystallization during SHR, which is similar to the repetitive deformation and heat treatment in GBE. The newly recrystallized grains result to more interactions of $\Sigma 3$ grain boundary via significant strain induced boundary migration, and then a high proportion of $\Sigma 9$ and $\Sigma 27$ grain boundary is achieved in the SHR process.
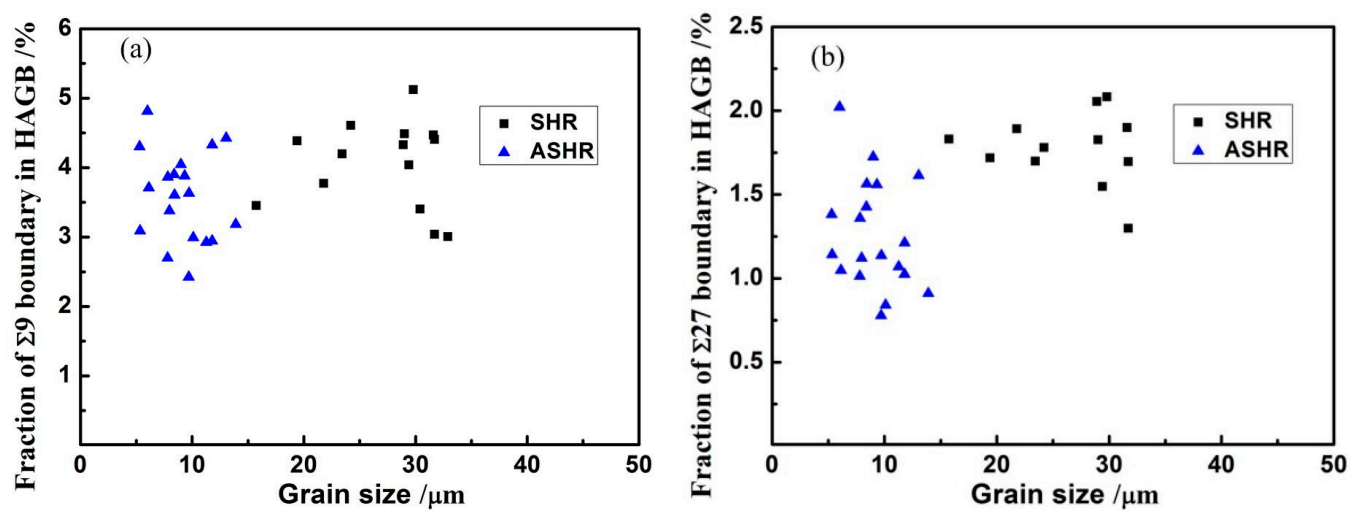

Figure 5. Fraction of $\Sigma 9$ (a) and $\Sigma 27$ (b) grain boundary in HGAB during SHR and ASHR process.

\subsection{Growth of Recrystallized Grains and Annealing Twin Nucleation}

The aspect ratio of recrystallized grains excluding the twin boundary in SHR and ASHR processes is shown in Figure 6. Every grain detected by EBSD software is considered as an equivalent ellipse shape via a specific method. Hence, the aspect ratio of grains is equal to that of the short and long axes of ellipse shape in the ranges of $0-1$. The aspect ratio of recrystallized grains is 0.496 and 0.52 in SHR and ASHR processes. This reveals grain boundary migration during growth exhibit as an apparent anisotropy rather than preferential growth. Thus, the behavior of strain-induced grain boundary migration is continuously generated during recrystallization in the SHR process. Meanwhile, in order to coordinate dislocation arrangement and reduce the interfacial energy, the annealing twins formed on the close packed surface $\{111\}$ perpendicular to the direction of grain boundary migration favor further grain growth.

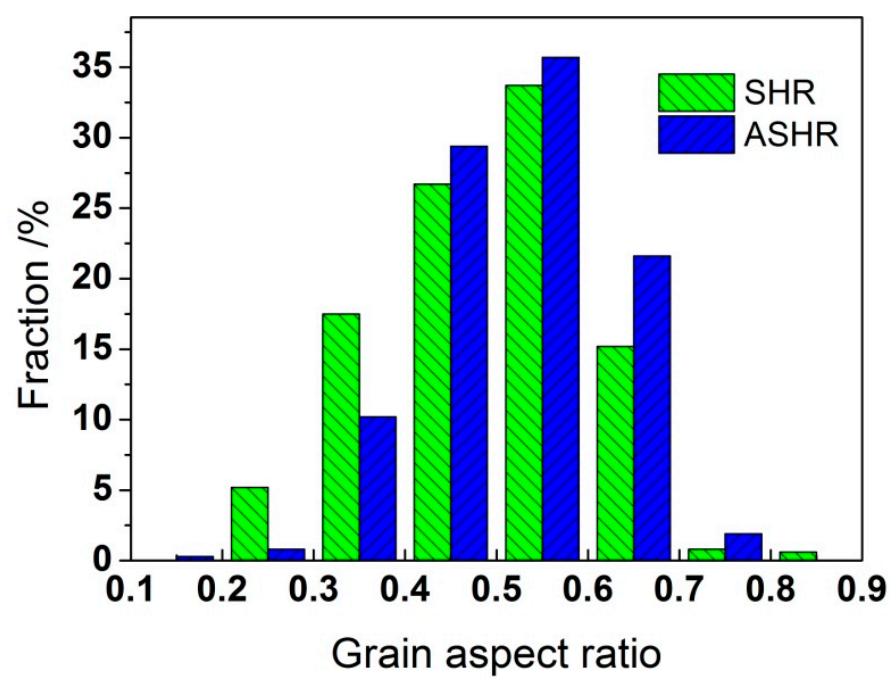

Figure 6. Fraction area of grain with different aspect ratio of recrystallized grains and grain aspect ratio in the SHR and ASHR processes. 
Figure 7 demonstrates the way of recrystallization nucleation and grain growth (Figure 7a) and the migration direction of grain boundary that promotes the nucleation of different annealing twin variants (Figure 7b). It is shown in Figure 7a that the relative lower dislocation density in hot deformation austenite is due to the recovery taking place. The preferential site of recrystallization nucleation is still near the grain boundaries of deformed austenite. At the initial stage of recrystallization, the bulging mechanism near the initial austenitic boundary has a dominant role in recrystallization along with the formation of annealing. Moreover, the recrystallization nucleation continues growing at the connected interface between the developing recrystallized grains and deformation austenite and it can continuously promote the frontier of recrystallization interface to migrate toward the interior of grain until recrystallization is completed. Since the density of dislocations in non-recrystallized and deformed austenite is apparently higher than that of the new recrystallized grains around it, newly recrystallized grains preferentially grow toward the high distortion regime. This implies that a large number of $\Sigma 3$ grain boundary interaction will take place owing to a greater degree of grain boundary migration. It is shown in Figure $7 \mathrm{~b}$ that the CSL boundary proportion increases with local grain boundary continuing bugling as well as the migration direction of bugling grain boundary constantly changes. Hence, a substantial migration of grain boundary is helpful to the generation of different orientation annealing twin variants.

(a)

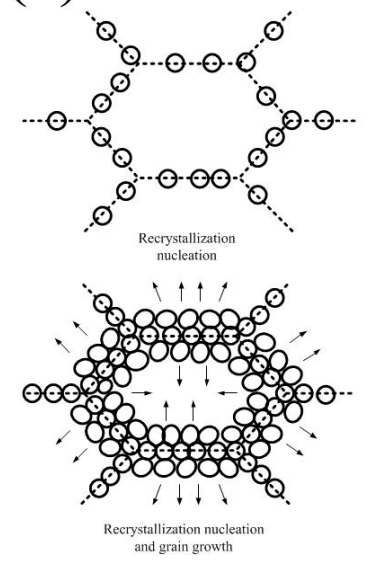

(b)

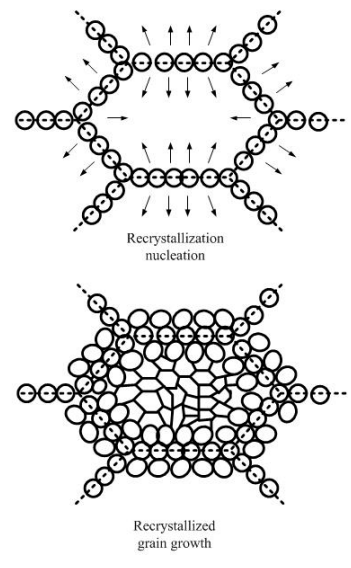

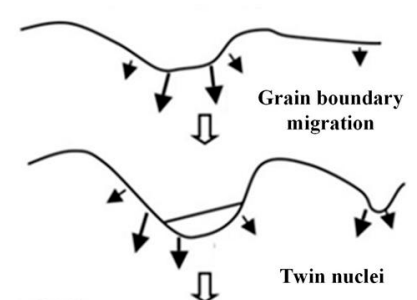

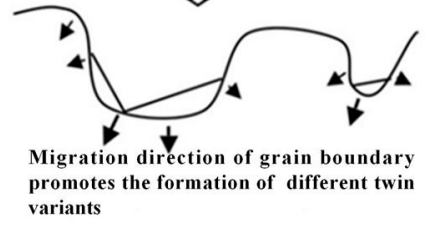

Figure 7. Schematic illustration of the recrystallization nucleation and grain growth (a) and the migration direction of grain boundary promotes the nucleation of different annealing twin variants during ASHR process (b).

\subsection{Vickers Micro Hardness and Tensile Properties}

Figure 8 a shows the Vickers micro hardness distribution along thickness direction of the specimen S-p3-70\% in SHR process and As-p3-83\%-1 in the ASHR process. It can be seen that the Vickers micro hardness of the specimen S-p3-70\% in SHR is greater than that of the specimen As-p3-83\%-1 in ASHR. It is the result of coarse grains and the annealing twins in SHR process. An interesting phenomenon can be seen, which is that the Vickers micro hardness distribution along the thickness direction is in the shape of a parabola. It indicates that the fine grains on the surface of the steel plate have been produced by intense shear deformation, and the Vickers micro hardness of the surface layer is obviously lower than that of the center. It is noted that the severe shear strain bands formed in the ASHR process are a typical feature [17]. Finer equiaxed grains at the shear strain bands have a relation with the lamellar spacing of the elongated grain boundaries. Additional severe shear stress increases the nucleation rate of recrystallization during ASHR, and reduces the grain size. 

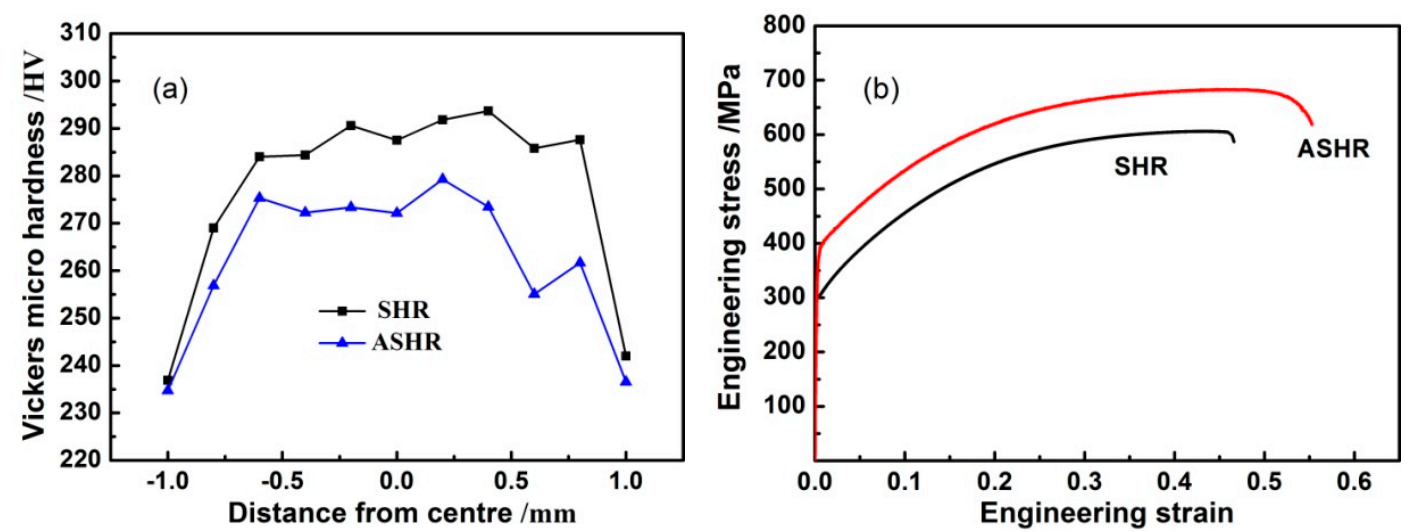

Figure 8. Vickers micro hardness distribution along thickness direction of the specimen S-p3-70\% in SHR process and As-p3-83\%-1 in ASHR process (a), engineering stress strain curves of the specimen S-p3-70\% in SHR process and As-p3-83\%-1 in ASHR process (b).

Figure $8 \mathrm{~b}$ shows the engineering stress strain curves of the specimen S-p3-70\% in SHR process and the specimen As-p3-83\%-1 in the ASHR process. It can be seen that the tensile property of the tested steel is improved due to the effective grain refinement caused by the ASHR process. The specimen S-p3-70\% in SHR process has yield strength of $300 \mathrm{MPa}$, tensile strength of $600 \mathrm{MPa}$ and elongation of $47 \%$. Nevertheless, the specimen As-p3-83\%-1 in the ASHR process has a yield strength of $410 \mathrm{MPa}$, tensile strength of $690 \mathrm{MPa}$ and total elongation of $60 \%$. The effects of grain refine and the annealing twin boundary through ASHR application is fairly productive for the austenite steels, compared with the SHR process. Hence, the effect of improvement by ASHR on tensile properties of austenite steel is significant.

\section{Conclusions}

The annealing twins of Fe-20Mn-4Al-0.3C austenitic steels in symmetric and asymmetric hot rolling are investigated in this work. The results can be summarized as follows.

(1) The average grain size is $26( \pm 9.6) \mu \mathrm{m}$ and $11( \pm 7.0) \mu \mathrm{m}$ for the tested steel in the SHR and ASHR processes. The density of high angle grain boundary (HAGB) and annealing twin boundary increase with the decrease in grain size. The annealing twin is obviously higher in ASHR than in the SHR process.

(2) The linear relation model between the logarithm of twin boundary density as a function of the logarithm of the grain size is established. The annealing twins formed on the (111) surface perpendicular to the migration direction of grain boundary favors further grow along this direction, resulting in a higher proportion of annealing twins in ASHR compared to that in the SHR process.

(3) The CSL boundary proportion increases with local grain boundary continuing bugling as well as the migration direction of bugling grain boundary constantly changes. A substantial migration of grain boundary is helpful to the generation of different orientation annealing twin variants.

(4) The tensile property of the tested steel is improved due to the severe shear stress increasing the nucleation rate of recrystallization and high density of annealing twins during the ASHR process. Hence, the effect of improvement by ASHR on tensile properties of austenitic steels is significant.

Author Contributions: C.L. conceived and designed the experiments; B.M. performed the experiments and wrote the paper; Y.S. wrote the paper; K.L. and J.D. analyzed the data.

Funding: This work was supported by the National Natural Science Foundation of China (grant number 51274062) and Research Fund for the Doctoral Program of Higher Education of China (grant number 20130042110040).

Conflicts of Interest: The authors declare no conflict of interest. 


\section{References}

1. Fullman, R.L.; Fisher, J.C. Formation of annealing twins during grain growth. J. Appl. Phys. 1951, 22, 1350-1355. [CrossRef]

2. Grube, W.L.; Rouze, S.R. The origin, growth and annihilation of annealing twins in austenite. Can. Metall. Q. 1963, 2, 31-52. [CrossRef]

3. Gleiter, H. The formation of annealing twins. Acta Metall. 1969, 17, 1421-1428. [CrossRef]

4. Meyers, M.A.; Murr, L.E. A model for the formation of annealing twins in F.C.C. metals and alloys. Acta Metall. 1978, 26, 951-962. [CrossRef]

5. Lin, B.; Jin, Y.; Hefferanc, C.M.; Li, S.F.; Lind, J.; Suter, R.M.; Bernacki, M.; Bozzolo, N.; Rollett, A.D.; Rohrer, G.S. Observation of annealing twin nucleation at triple lines in nickel during grain growth. Acta Mater. 2015, 99, 63-68. [CrossRef]

6. Field, D.P.; Bradford, L.T.; Nowell, M.M.; Lillo, T.M. The role of annealing twins during recrystallization of Cu. Acta Mater. 2007, 55, 4233-4241. [CrossRef]

7. Jin, Y.; Lin, B.; Rollett, A.D.; Rohrer, G.S.; Bernacki, M.; Bozzolo, N. Thermo-mechanical factors influencing annealing twin development in nickel during recrystallization. J. Mater. Sci. 2015, 50, 5191-5203. [CrossRef]

8. Dash, S.; Brown, N. An investigation of the origin and growth of annealing twins. Acta Metall. 1963, 11, 1067-1075. [CrossRef]

9. Pande, C.S.; Imam, M.A.; Rath, B.B. Study of annealing twins in FCC metals and alloys. Metall. Trans. A 1990, 21, 2891-2896. [CrossRef]

10. Jin, Y.; Lin, B.; Bernacki, M.; Rohrer, G.S.; Rollett, A.D.; Bozzoloa, N. Annealing twin development during recrystallization and grain growth in pure nickel. Mater. Sci. Eng. A 2014, 597, 295-303. [CrossRef]

11. Mahajan, S.; Pande, C.S.; Imam, M.A.; Rath, B.B. Formation of annealing twins in F.C.C. crystals. Acta Mater. 1997, 45, 2633-2638. [CrossRef]

12. Kumar, M.; Schwartz, A.J.; King, W.E. Microstructural evolution during grain boundary engineering of low to medium stacking fault energy fcc materials. Acta Mater. 2002, 50, 2599-2612. [CrossRef]

13. Randle, V. Mechanism of twinning-induced grain boundary engineering in low stacking-fault energy materials. Acta Mater. 1999, 47, 4187-4196. [CrossRef]

14. Randle, V. Twinning-related grain boundary engineering. Acta Mater. 2004, 52, 4067-4081. [CrossRef]

15. Wang, W.; Lartigue-Korinek, S.; Brisset, F.; Helbert, A.L.; Bourgon, J.; Baudin, T. Formation of annealing twins during primary recrystallization of two low stacking fault energy Ni-based alloys. J. Mater. Sci. 2015, 50, 2167-2177. [CrossRef]

16. Randle, V. Role of grain boundary plane in grain boundary engineering. Mater. Sci. Technol. 2010, 26, 774-780. [CrossRef]

17. Li, C.; Ma, B.; Song, Y.; Zheng, J.; Wang, J. Grain refinement of non-magnetic austenitic steels during asymmetrical hot rolling process. J. Mater. Sci. Technol. 2017, 33, 1572-1576. [CrossRef] 